\title{
2 ortede.
}

Pein פBerf murbe von mir to oft - fdon ben 6 Nov. 1806 bas exfemal - angefanget, unb unterbrodien als biefes Berfden. Dar:

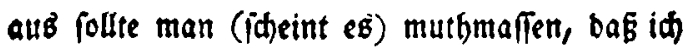
moine cignen jåbrliden Bereblungen unb Er. bebungen im Buche von Beit zu Beit nahgetra, gen, unb nachgefhoffen batte; unb id bátte ben

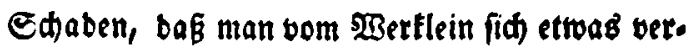
fpråd). Simmt alfo eir irrender Refer baffelbe barum in bie Sanb, um fid) barin auf feinem 


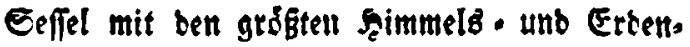
Etưrmern, bie es je gegeben, in Befaunt(h)aft

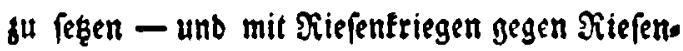
fhlangen auf Riefengebirgen - mit reiffenten

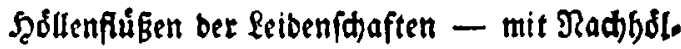
len voll Sreusfeuer romantifher Sieber. -Qua, len - mit meibliden Exempeln uno mânnlident Eri - teufeln - ja mit Ober , Şăuptern, melde auf Staatzigebáuben als Sraden. Sisppe von Ibrainen = Rinnen ben Regen in bie Iraufe vet: wandeln -; nimmt barum ber lefer geneigt mein 'Suth in bie ḩand: fo wart' er fo lange, bis ers burdigelefen hat, um nud einem anbern 3u greifen, worin bergleiden Caden mizflid) fee. ben. SBabrlid in biefem febt nid)tr. -

Einige wenige harntlofe, fabuldofe, lidtlofe, glanglofe feute mit âbnliden Ediđifalen, burd). leben barin ibr Dftabbantden - bas Gange ift 
ein ftillenbes Etilleben - eine SBBiege erwad) pener fefer zum Farniente - ein leifes graues

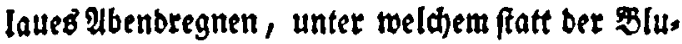
men etwan bie unf(d)einbare Erbe ausibuftet, wo.

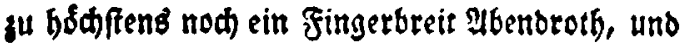
beri Stralen Abenbftern Eommen modten.

Weiter gibtò nid)ts̉ batin, im Bud).

3senbet man fidh freilid) am Hfer une von biefem fillen Mierrden unb blidt lanbeintwáts, in Dab Treiben unb Eaufen jegeiger হెeit uno Po. litik - fammt beren baran gebăngten \$enfaen: fo erftaunt man über ben Unterífico unb Glan: biefer Sreiber unb filufer, unb vergleidit fie balb mit ben fogenannten Bergnånnleill, welde neben ben Bergfnappen fo ausinegmenb arbeiten, in Stollen fabren, Fáuftel handgaben, Erbaaten, Bergąuber ausigießen, Şâpel jiefen - - 
VI

Freilid thun bie sebolbe eigettlid nid)(s, unb bie Thátigteit bleibt mebr afuftifa) unb op. tifh, toåleenb ber liegente Fergfnappe (d)ónes Ery geminnt. Eo baben leife Menidjen tiefer, mentgftens frudtbringenber in bie Sufunft bitt. ein gebanbelt als laute; ben Stillen im Lan. be wurbe iffers Raum unb Beit bas Epradige. mólbe, bas fie fu ben Rauten auffer fanbes mad)te.

Eo m\&ge benn ben meifen Eleinen P\&mmer. toolfen biefer Bogett ein Durdjug am literaris (A)en geftirnten Scimmels. Benotlbe ober Rabens Betoflbe verftattet werden, obglcid Låmmermol. ten weber bliken unb bonnern, nod erfdlagen, unb erfăufen. Id) für meine \$erion betente getn, baß̧ ein fold)es vertdien, wie id eben bier ber Belt barreidbe, mir, weun id)s bon cinem Dritten betáme, ein gefunbnes Effen wa. 
re, unb leben in mid bråd)te; benn id twirb' (E) auf bie red)te Nobemberz, ber wie ber 2pril und ber Teufel immer (chmuşig abjtebt, ober and) fonft bei frar.

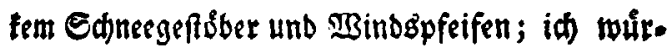
be an einen foldjen 21 bent meft f̧ols nad)legen laffer und bie Stiefel augizieben, ferner bie po. litifłen zeitungen einen $\mathfrak{T}$ ag ju lange liegen ober fie ungelejen fortlaufen laffen - id wưrbe Mits leib mit jeber sutjhe baben, bie jum Tlgee füfo. re; unb mir blog ein Şlas unb ein vermunfs tiges 2abentbeod aus ber Rintbeit beftellen, und fúr ben Niorgen ein balbes Roth Raffee Heber.

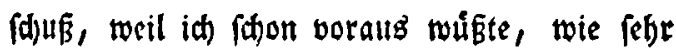

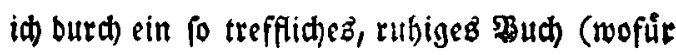
bem Derfaffer ẹwiger Dant fet!) zur An. fpannung fưr ein eignes glánzenbes ausigeholet båtte. . . 


\section{VIII}

Eo wưrb' id daš 5 Berfden Iejen; abet leiber $\mathfrak{b} \mathfrak{a b}$ id $e \mathfrak{B}$ felber vorber gemact.

Baitenth Sen rzten Sennev I 81 I.

Jean Yvaul Fr. $\mathfrak{R}$ idftet.

Bot: 